\title{
CARIOGENIC EFFECT OF DIETARY HABITS AMONG CARIES FREE AND EARLY CHILDHOOD CARIES CHILDREN
}

\author{
Reham S. Soliman 1 BDS, Ahmed Abdel Rahman2 PhD, Karin ML Dowidar3 PhD
}

\begin{abstract}
INTRODUCTION: Early Childhood Caries (ECC) remains an important childhood disease affecting a considerable portion of young children. ECC has been associated with inappropriate feeding patterns and excess consumption of fermentable carbohydrates.

OBJECTIVES: The purpose of this study was to compare children affected by ECC and S-ECC and those who are caries free regarding their dietary habits.

MATERIALS AND METHODS: Thirty children aged 2-6 years free from any systemic disease were selected for this study. Children were recruited from those attending the outpatient clinic at the Faculty of Dentistry, Alexandria University. The children were divided into three groups. Group 1 consisted of 10 children who had ECC. Group 2 consisted of 10 children presenting with S-ECC, while Group 3 included 10 children who were caries free serving as the control group. After clinical examination, the children's parents were asked to complete a standardized 3-day food diary form where they reported all the foods, beverages and snacks the child consumed over a 3-day period. Finally, a fermentable carbohydrate analysis was performed to determine the average number of exposures per day.

RESULTS: Significant associations were found between the increasing severity of caries and the feeding habits of the children. The total carbohydrate scores for the caries free, ECC, and S-ECC groups were $90.00 \pm 17.71,104.56 \pm 38.33$, and $161.33 \pm 24.12$ respectively. There was a statistically significant difference among the three groups $(\mathrm{P}<0.0001)$.

CONCLUSIONS: The increase in fermentable carbohydrate intake is associated with Early Childhood Caries.

KEYWORDS: dietary habits, early childhood caries, severe early childhood caries, fermentable carbohydrates.
\end{abstract}

\footnotetext{
- Demonstrator of Pediatric Dentistry, Faculty of Dentistry, Alexandria University, Alexandria, Egyp

2- Professor of Dental Public Health, Faculty of Dentistry, Alexandria University, Alexandria, Egypt

3- Professor of Pediatric Dentistry, Faculty of Dentistry, Alexandria University, Alexandria, Egypt
}

\section{INTRODUCTION}

Dental caries is the single most common chronic childhood disease (1). It is an infectious microbiologic disease of the teeth that results in localized dissolution and destruction of the calcified tissues (2). Early Childhood Caries is a form of severe dental decay that affects the primary teeth of infants and toddlers (3). Early Childhood Caries is defined as the presence of one or more decayed (non-cavitated or cavitated), missing (due to caries) or filled tooth surfaces in any primary tooth in a child under age of six, whereas, severe early childhood caries (S-ECC) is any sign of smooth surface caries in a child younger than three years of age (4) and this definition has been adopted by the American Academy of Pediatric Dentistry (5).

Dental caries occurs when a susceptible tooth surface is colonized with cariogenic bacteria and a dietary source of sucrose or refined sugar is present. The fermentation process of refined carbohydrates by pathogenic bacteria results in lactic acid that dissolves the hydroxyapatite crystal structure of the tooth (6). Early Childhood Caries is often associated with inappropriate feeding habits where the child is put to bed with a nursing bottle holding milk or a sugar-containing beverage. The child falls asleep and the liquid pools around the teeth but the lower anterior teeth tend to be protected by the tongue. The carbohydrate containing liquid provides an excellent culture medium for acidogenic microorganisms (7). Diet plays a critical role in acquisition of the bacterial infection and ECC development. Despite the fact that most children with S-ECC are frequently exposed to cariogenic sweets and drinks, individual variations still exist $(8,9)$.
Dental caries thus results when frequent or prolonged exposure of dental plaque to dietary carbohydrate and consequent acid generation overcome tooth-protective mechanisms leading to demineralization of hard tooth structure (10). Total fermentable carbohydrate consumption especially sucrose and the frequency of intake are associated with dental caries (11-13). Sucrose is the most cariogenic fermentable carbohydrate (14). Frequent sucrose exposures begin a series of changes that promotes the growth of highly acidogenic bacteria that eventually leads to caries (2). Sucrose induces biochemical changes in the dental plaque composition in addition to microbiological aspects. The concentration of calcium, inorganic phosphorous and fluoride ions in dental plaque decreases with increased frequency of sucrose exposure. Calcium and phosphorous are important in the equilibrium between demineralization and remineralization of enamel acting as a "saturation buffer" $(15,16)$.

Although the plaque and salivary levels of microorganisms are influenced by frequency of sugar intake, their significance with regard to caries activity is less well documented (18-20). The frequency of ingestion and the form of the fermentable carbohydrate are the critical factors in the cariogenicity of sugar. Products that are sticky, retained for long periods in the oral cavity or consumed with high frequency have a higher cariogenicity than foods that are eliminated quickly (13). Increased frequency of eating is considered to be the primary dietary factor associated with the caries process. Thickened dental plaque, food debris, anatomic tooth abnormalities and frequent consumption of cooked starches, simple sugars or processed sugar-starch combinations will sustain an oral 
environment that promotes demineralization in preference to remineralization. With increased eating frequency, there is an expected increase in the total fermentable carbohydrate intake (21).

From the age of 1 to 5 years, the child is introduced to a variety of new foods. It is at that time when healthy meal and snack patterns should be instilled. Frequent cariogenic snacks or continual sipping of cariogenic liquids place the child at high risk for caries development (13).

Foods considered to be cariogenic due to their high fermentable carbohydrate content include: candy, cookies, cakes, sweetened beverages (including fruit juices), fruit rollups, dried fruits, breakfast bars, ketchup, and to a lesser extent chocolate milk and whole grain products. Starch is often regarded as a relatively low cariogenic carbohydrate such as rice, potatoes, pasta, and bread except if finely ground, heat treated and frequently eaten. Additionally, starch that is retained on the teeth for a long time is considered cariogenic (13).

One of the most common approaches undertaken in dietary screening is the food intake diary. It involves a nutrition history questionnaire which is then evaluated to determine whether the patient needs further nutrition intervention. Assessment of the cariogenic potential of the child's diet involves an evaluation of the fermentable carbohydrate intake. The frequency of intake and the consistency of the refined carbohydrates are key factors in the initiation and continuation of the caries process (22). The aim of this study was to compare children who are caries free, those with ECC and those with S-ECC regarding dietary and snacking habits.

\section{MATERIALS AND METHODS}

A case control study was designed to compare the dietary habits of children with and without ECC. Thirty healthy children aged 2-6 years (24-71 months) were selected for this study. Twenty of which presented early childhood caries and ten were caries free. Children were recruited from those attending the outpatient clinic, Faculty of Dentistry, Alexandria University.

Criteria for patient selection (23):

Children should:

1. Have only primary teeth.

2. Be of middle socio-economic status.

Grouping:

Children chosen for this study were divided into 3 groups following Drury et al (4) criteria:

Group 1: consisted of 10 children that had Early Childhood Caries

Group 2: consisted of 10 children that had Severe Early Childhood Caries.

Group 3: control, consisted of 10 children that were caries free.

Caries was diagnosed using visual and tactile examination after thorough drying (4). An explorer was not used or used without significant axial force to clean debris from a pit or fissure. Both non-cavitated and cavitated carious lesions were included. Non-cavitated lesions had no clinically visible loss of enamel structure and there was no evidence of undermining (4). In pits and fissures, non-cavitated lesions presented as distinct chalky white enamel directly adjacent to or in a pit or fissure or as light to dark brown discoloration no larger than the size of a pit or fissure. In smooth surfaces, non-cavitated lesions presented as distinct chalky white enamel, usually adjacent or close to the gingival margin. These lesions usually occur in areas where plaque accumulates and are parallel to the gingival margin. The cavitated lesions (24) whether in a pit or fissure, or on a smooth surface had visual evidence of caries on the occlusal, buccal, or lingual surfaces or, an unmistakable cavity, or undermined enamel, or a detectably softened floor or wall.

The child's parent was given a standardized 3- day food intake chart (25). This is a special form on which the child's parent enters all the foods, beverages and snacks the child has consumed over a 3- day period. At least one weekend day was included in the record as eating habits often differ on weekends.

After these procedures were done, the child's parents were given the following instructions and dismissed: the child was to return after 3 days after completing the 3 -day food intake chart accurately. The parent should not try to change the child's eating habits while filling in the chart.

The child's food record was evaluated to determine the amount of freely fermentable carbohydrates (4). All food containing sugar or added sugar was included excluding fresh juices, whole wheat bread, and fresh fruits. Sugars in a retentive form i.e. those that can be retained on the tooth were determined. Examples include: sauces (tomato ketchup), toffee, gum, and caramel, white bread, cornflakes, dried fruits, chips, cake, and jam. Such sugars were distinguished from those that are easily washed out as juice, carbonated soft drinks, jelly, ice-cream, and honey. Fermentable carbohydrate exposures were then recorded in the schedule, bearing the fact that an interval of 30 minutes or more was considered a different exposure. Furthermore, exposures were classified as being taken either during meals or between meals. The total number of exposures was then multiplied by 20 . This is because 20 minutes may be considered the minimal time each exposure permits acid concentrations to be available in the bacterial plaque. The number of exposures for each patient was thus determined and compared with the normal average of a 100 exposures per day (4). The child was asked to return for another visit so that all teeth that needed restorations were completed and all patient requirements regarding dental treatment were fulfilled.

Statistical analysis was carried out using SPSS program (Statistical Package for Social Sciences) version 20. Comparison among the three study groups was done using F test for comparison of means (age, ....) and chi square test for qualitative variables (sex, feeding, ....). Kruskal Wallis test was used to compare the three study groups regarding the number of events of eating solid and liquid carbohydrates during and between meals.

\section{RESULTS}

Table 1 shows the comparison of sex, age, and dmfs among the three study groups. In the caries free group $80 \%$ were males, whereas in each of the ECC and S-ECC groups, females constituted $80 \%$ of the sample. There was a significant difference between the sex distribution in the three groups $(\mathrm{P}=0.007)$. The age of children in the study ranged from 3- 6 years. The difference between the groups regarding mean age was statistically significant $(\mathrm{P}=0.007)$. The dmfs of the children extended up to 30 affected surfaces. The mean dmfs in the ECC group was $3.7 \pm 1.0$ 
and in the S-ECC was $13.8 \pm 8.3$. There was a significant difference among the three groups $(\mathrm{P}<0.0001)$.

Table 1: Comparison of sex, age, and dmfs among the three study groups

\begin{tabular}{|c|c|c|c|c|c|}
\hline \multicolumn{2}{|c|}{ Variables } & \multirow{2}{*}{$\begin{array}{c}\begin{array}{c}\text { Caries } \\
\text { free }\end{array} \\
8(80)\end{array}$} & \multirow{2}{*}{$\begin{array}{l}\text { ECC } \\
2(20)\end{array}$} & \multirow{2}{*}{$\begin{array}{l}\text { S-ECC } \\
2(20)\end{array}$} & \multirow{3}{*}{\begin{tabular}{|c|} 
P value \\
$0.007^{*}$
\end{tabular}} \\
\hline Sex & $\begin{array}{c}\text { Male: } \mathbf{n} \\
(\%)\end{array}$ & & & & \\
\hline & $\begin{array}{c}\text { Female: } \\
\text { n (\%) }\end{array}$ & $2(20)$ & $8(80)$ & $8(80)$ & \\
\hline \multirow[t]{2}{*}{ Age } & $\begin{array}{l}\text { Min- } \\
\max \end{array}$ & $3-5$ & $4-6$ & 4- 5 & \multirow[t]{2}{*}{$0.007^{*}$} \\
\hline & $\begin{array}{c}\text { Mean } \pm \\
\text { SD }\end{array}$ & $\begin{array}{c}3.86 \pm \\
0.81\end{array}$ & $\begin{array}{c}4.90 \\
\pm \\
0.69\end{array}$ & $\begin{array}{c}4.56 \pm \\
0.46\end{array}$ & \\
\hline \multirow[t]{2}{*}{ dmfs } & $\begin{array}{l}\text { Min- } \\
\text { max }\end{array}$ & $0-0$ & $2-5$ & $5-30$ & \multirow[t]{2}{*}{$<0.0001^{*}$} \\
\hline & $\begin{array}{c}\text { Mean } \pm \\
\text { SD }\end{array}$ & $0 \pm 0$ & $\begin{array}{c}3.7 \pm \\
1.0\end{array}$ & $\begin{array}{c}13.8 \pm \\
8.3\end{array}$ & \\
\hline
\end{tabular}

*: $\quad$ Statistically significant at $\mathrm{P}<0.05$

Table 2 and Figure 1 show the comparison of the mean number of events of eating fermentable carbohydrates among the three study groups. The mean number of events of eating sugars in solution during meals in caries free, ECC and S-ECC groups was $1.45 \pm 1.44,2.00 \pm 2.00$ and $2.67 \pm$ 2.00 respectively. The difference among the three groups was not statistically significant $(\mathrm{P}=0.37)$. The mean number of events of eating sugars in solution between meals was $2.00 \pm 1.48,2.44 \pm 1.42,6.00 \pm 3.54$ respectively. There was a statistically significant difference among the three groups $(\mathrm{P}=0.005)$. The mean number of events of eating solid retentive sugars during meals was $4.73 \pm 1.74,5.22 \pm 1.39$, $7.11 \pm 1.62$ respectively for the three groups. The difference among the three study groups was statistically significant $(\mathrm{P}=0.02)$. The mean number of events of eating solid retentive sugars between meals for the caries free, ECC and S-ECC groups was $5.45 \pm 1.97,7.89 \pm 3.02,8.44 \pm 3.21$ respectively. There was a statistically significant difference among the three study groups $(\mathrm{P}=0.05)$. The total carbohydrate scores for the caries free, ECC, and S-ECC groups were $90.00 \pm 17.71,104.56 \pm 38.33$, and $161.33 \pm$ 24.12 respectively. There was a statistically significant difference among the three groups $(\mathrm{P}<0.0001)$.

Table 3 shows the correlation between the number of events of eating sugar in solution and solid forms during and between meals on one side and the dmfs on the other side. The correlation between the number of events of eating sugar in solution during meals and dmfs was not statistically significant $(\mathrm{rho}=0.11, \mathrm{P}=0.63$ ). The moderate positive correlation between the number of events of eating sugars in solution between meals and dmfs was statistically significant ( $\mathrm{rho}=0.61, \mathrm{P}=0.001)$. The moderate positive correlation between eating solid retentive sugars during meals and $\mathrm{dmfs}$ was statistically significant ( $\mathrm{rho}=0.49$, $\mathrm{P}=0.007$ ). Similarly, a moderate positive statistically significant correlation existed between the number of events of eating solid retentive sugars between meals and dmfs $(\mathrm{rho}=0.40, \mathrm{P}=0.03)$. There was a strong positive correlation between the total carbohydrate score and the dmfs of the children. This correlation was statistically significant $(\mathrm{P}<0.0001)$.

Table 2: Comparison of the number of events of eating sugar in solution and solid retentive sugars during and between meals among the three study groups

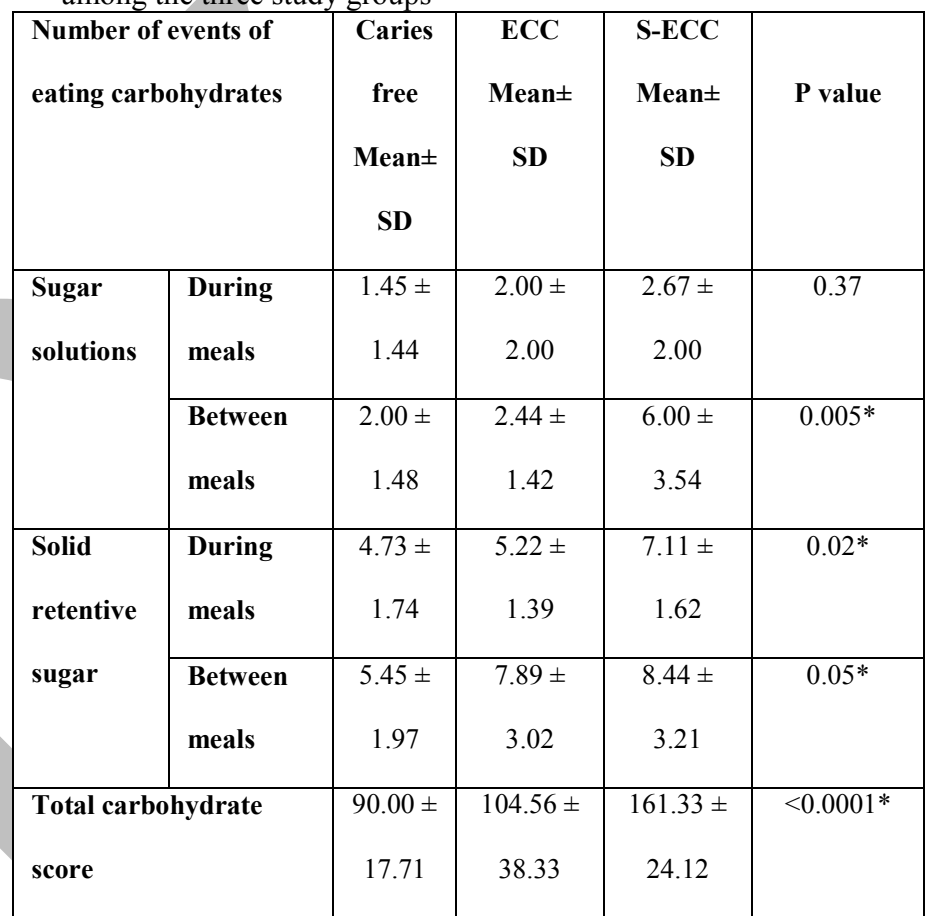

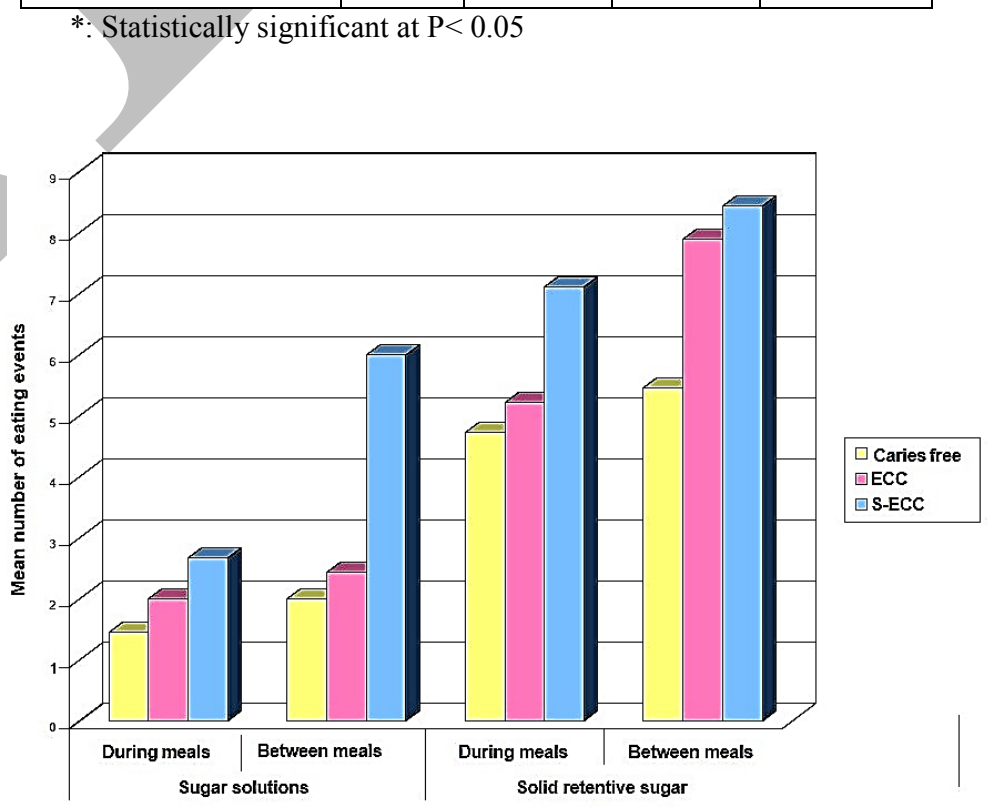

Figure 1: Comparison of the number of events of eating sugar in solution and solid retentive sugars during and between meals among the three study groups 
Table 3: Correlation between the number of events of eating sugar in solution and solid forms during and between meals on one side and dmfs on the other side

\begin{tabular}{|l|c|c|c|c|c|}
\hline dmfs & $\begin{array}{c}\text { Sugar } \\
\text { solution } \\
\text { during } \\
\text { meals }\end{array}$ & $\begin{array}{c}\text { Sugar } \\
\text { solutions } \\
\text { between } \\
\text { meals }\end{array}$ & $\begin{array}{c}\text { Solid } \\
\text { retentive } \\
\text { sugar } \\
\text { during } \\
\text { meals }\end{array}$ & $\begin{array}{c}\text { Solid } \\
\text { retentive } \\
\text { sugar } \\
\text { between } \\
\text { meals }\end{array}$ & $\begin{array}{c}\text { Total } \\
\text { carbohydrate } \\
\text { score }\end{array}$ \\
\hline Rho & 0.11 & 0.61 & 0.49 & 0.40 & 0.75 \\
P & 0.63 & $0.001^{*}$ & $0.007^{*}$ & $0.03 *$ & $<0.0001^{*}$ \\
value & & & & \\
\multicolumn{2}{|l}{ rho: Spearman rho test } \\
*: Statistically significant at $\mathrm{P}<0.05$
\end{tabular}

\section{DISCUSSION}

Early Childhood Caries remains an important childhood disease affecting a considerable portion of young children (26). In order to avoid bias as much as possible in the present study, the sample chosen were of the same socioeconomic class as that was confirmed to be a caries determinant factor. In a descriptive and comparative analysis of the three study groups it was found that the severity of ECC increases significantly with advancing age groups. This has also been concluded by Declerck et al (26) who observed significant associations between caries experience and advancing age. It had been mentioned that age was found to be the most important predictor of caries experience and that the caries approximately doubles for every additional year of age $(27,28)$. It was also observed that there was a significant predilection towards females with increasing caries severity. A possible explanation for these findings may be that earlier emergence of primary teeth in girls than in boys prolongs their exposure to the oral environment (26).

Dental caries is known to be a diet-dependent bacterial disease. Among the dietary components, sucrose is considered the most critical, regarding the biochemical and microbiological change that it induces in dental plaque composition. In the present study, the role of fermentable carbohydrates in ECC, S-ECC, and caries free groups was extensively studied. Fermentable carbohydrate intake was not only investigated regarding its frequency but it was further classified according to its physical properties and time of intake during the day. This is because the extent to which the physical properties determine the retention or breakdown of foods in the mouth has been suggested as an important determinant in cariogenicity (29).

There was a significant increase in the number of events of fermentable carbohydrate exposures between the three study groups, indicating that there is a role of fermentable carbohydrates in the increasing severity of caries. It showed a significant positive correlation between the total carbohydrate intakes whether in eating sugar in solution or solid retentive forms during and between meals and the dmfs of the subjects under study. These results are in accordance with Beighton et al (20) who reported a positive relation between sugar intake and caries experience. Moreover, Cury et al (30) also showed that the concentration of insoluble polysaccharides in dental plaque depended on sucrose exposure. This insoluble polysaccharide was shown to be responsible for the high cariogenicity of sucrose (15). Similarly, studies by Santos et al (25) showed that children with S-ECC ingested sugar more frequently than those with ECC or those who were caries free. It can be concluded therefore that the cariogenicity of sugars and fermentable carbohydrates was higher when consumed more frequently (as between meals) than when included during meals.

On the other hand, Marshall et al (31) and Burt and Pai (32) stated that the relationship between sugar consumption and caries is very weak. These results were however justified by the suggestion that fluoride intake had increased and hence compensated for this relationship. This applies to developed countries rather than developing ones.

It has been established by earlier studies that sucrose is more cariogenic than lactose, glucose, fructose, and starch, and that its cariogenic potential can be varied by the frequency of its consumption. Earlier investigations have also concluded that the frequency of intake of fermentable carbohydrates especially sucrose, can significantly influence the plaque and salivary levels of S. mutans, lactobacilli, and yeasts (17-19).

\section{CONCLUSIONS}

1. Children with severe early childhood caries demonstrated the highest fermentable carbohydrate intake.

2. Eating sugar in solution or solid retentive forms during and between meals were significant factors affecting caries

\section{CONFLICT OF INTEREST}

The authors declared that they have no conflicts of interest.

\section{REFERENCES}

1. US Department of Health and Human Services. Oral Health in America: a report of the surgeon General. Rockville, MD: US Department of Health and Human Services, National Institutes of Health, National Institute of Dental and Craniofacial Research; 2000.

2. Roberson TM, Heyman H, Swift EJ, Cariology. In Art and Science of Operative Dentistry. $4^{\text {th }}$ ed. Missouri: Mosby; 2002: 63-130.

3. Horowitz HS. Research issues in early childhood caries. Community Dent Oral Epidemiol. 1998; 26(1 Suppl): 6781.

4. Drury TF, Horowitz AM, Ismail AI, Maertens MP, Rozier RG, Selwitz RH. Diagnosing and reporting early childhood caries for research purposes. A report of a workshop sponsored by the National Institute of Dental and Craniofacial Research, the Health Resources and Services Administration, and the Health Care Financing Administration. J Public Health Dent. 1999; 59:192-7.

5. American Academy of Pediatric Dentistry. Policy on Early Childhood Caries (ECC): Classifications, Consequences, and Preventive Strategies. Oral Health Policies. 2016; 38:52-4. Available from:

http://www.aapd.org/media/Policies_Guidelines/P_ECCCla ssifications1.pdf

6. Caufield PW, Griffen AL. Dental caries. An infectious and transmissible disease. Pediatr Clin North Am. 2000; 47:1001-19.

7. McDonald Ralph E., Avery David R., Dental caries in the child and adolescent. In: Dentistry for the child and adolescent. 10 ${ }^{\text {th }}$ ed. Missouri: Mosby;2016; 203-35.

8. Johnsen DC, Bhat M, Kim MT, Hagman FT, Allee LM, Creedon RL, et al. Caries levels and patterns in head start 
children in fluoridated and non-fluoridated, urban and nonurban sites in Ohio, USA. Community Dent Oral Epidemiol. 1986; 14:206-10.

9. Korenstein K, Echeverri EA, Keene HJ. Preliminary observations on the relationship between mutans streptococci and dental caries experience within black, white, and Hispanic families living in Houston, Texas. Pediatr Dent. 1995; 17:445-50.

10. Sissons CH, Anderson SA, Wong L, Coleman MJ, White DC. Microbiota of plaque microcosm biofilms: effect of three times daily sucrose pulses in different simulated oral environments. Caries Res. 2007; 41:413-22.

11. Gustafsson BE, Quensel CE, Lanke LS, Lundqvist C, Grahnen H, Bonow BE, et al. The Vipeholm dental caries study; the effect of different levels of carbohydrate intake on caries activity in 436 individuals observed for five years. Acta Odontol Scand. 1954; 11:232-64.

12. König KG, Schmid P, Schmid R. An apparatus for frequency-controlled feeding of small rodents and its use in dental caries experiments. Arch Oral Biol. 1968; 13:13-26.

13. Bibby BG. The cariogenicity of snack foods and confections. J Am Dent Assoc. 1975; 90:121-32.

14. Tinanoff N. Association of diet with dental caries in preschool children. Dent Clin North Am. 2005; 49:725-37.

15. Pearce EIF. Plaque minerals and dental caries. NZ Dental J. 1998; 94:12-5.

16. Cury JA, Rebelo MA, Del Bel Cury AA, Derbyshire MT, Tabchoury CP. Biochemical composition and cariogenicity of dental plaque formed in the presence of sucrose or glucose and fructose. Caries Res. 2000; 34:491-7.

17. Beighton D, Hayday H. The establishment of the bacterium Streptococcus mutans in dental plaque and the induction of caries in macaque monkeys (Macaca fascicularis) fed a diet containing cooked-wheat flour. Arch Oral Biol. 1984; 29:369-72.

18. Carlsson J. Microbial aspects of frequent intake of products with high sugar concentrations. Scand J Dent Res. 1989; 97:110-4.

19. Kristoffersson K, Birkhed D. Effects of partial sugar restriction for 6 weeks on numbers of Streptococcus mutans in saliva and interdental plaque in man. Caries Res. 1987; 21:79-86

20. Beighton D, Adamson A, Rugg-Gunn A. Associations between dietary intake, dental caries experience and salivary bacterial levels in 12-year-old English schoolchildren. Arch Oral Biol. 1996; 41:271-80.

21. Mobley CC. Nutrition and dental caries. Dent Clin N Am. 2003;47: 319-36.

22. Harris Norman O, Christen Arden G, Clinical procedures for controllong plaque diseases. In: Primary Preventive Dentistry. $4^{\text {th }}$ ed. Norwalk, CT: Appleton and Lange; 1995:555-90.

23. de Carvalho FG, Silva DS, Hebling J, Spolidorio LC, Spolidorio DM. Presence of mutans streptococci and Candida spp. in dental plaque/dentine of carious teeth and early childhood caries. Arch Oral Biol. 2006; 51:1024-8.

24. World Health Organization, Oral Health Surveys- basic methods, $4^{\text {th }}$ ed. Geneva: World Health Organization; 1997.

25. Nobre dos Santos M, Melo dos Santos L, Francisco SB, Cury JA. Relationship among dental plaque composition, daily sugar exposure and caries in the primary dentition. Caries Res. 2002; 36:347-52.

26. Declerck D, Leroy R, Martens L, Lesaffre E, Garcia-Zattera MJ, Vanden Broucke S, et al. Factors associated with prevalence and severity of caries experience in preschool children. Community Dent Oral Epidemiol. 2008; 36:16878.

27. Gibson S, Williams S. Dental caries in pre-school children: associations with social class, toothbrushing habit and consumption of sugars and sugar-containing foods. Further analysis of data from the National Diet and Nutrition Survey of children aged 1.5-4.5 years. Caries Res 1999; 33:101-13.

28. Milgrom P, Riedy CA, Weinstein P, Tanner AC, Manibusan L, Bruss J. Dental caries and its relationship to bacterial infection, hypoplasia, diet, and oral hygiene in 6- to 36month-old children. Community Dent Oral Epidemiol. 2000; 28:295-306.

29. Caldwell RC. Physical properties of foods and their cariesproducing potential. J Dent Res. 1970; 49:1293-8.

30. Cury JA, Rebello MA, Del Bel Cury AA. In situ relationship between sucrose exposure and the composition of dental plaque. Caries Res. 1997; 31:356-60.

31. Marshall TA, Broffitt B, Eichenberger-Gilmore J, Warren JJ, Cunningham MA, Levy SM. The roles of meal, snack, and daily total food and beverage exposures on caries experience in young children. J Public Health Dent. 2005; 65:166-73.

32. Burt BA, Pai S. Sugar consumption and caries risk: a systematic review. J Dent Educ. 2001; 65:1017-23. 